九州大学学術情報リポジトリ

Kyushu University Institutional Repository

\title{
Basic Studies on Fracture Toughness of Sugi and Acoustic Emission
}

Ohuchi, Takeshi

Laboratory of Woodworking, Department of Technology, Fukuoka University of Education

Hermawan, Andi

Laboratory of Wood Material Technology, Sustainable Bioresources Science, Department of Agroenvironmental Sciences, Faculty of Agriculture, Kyushu University

Fuj imoto, Noboru

Laboratory of Wood Material Technology, Sustainable Bioresources Science, Department of Agroenvironmental Sciences, Faculty of Agriculture, Kyushu University

https://doi.org/10.5109/19536

出版情報: 九州大学大学院農学研究院紀要. 56 (1), pp.99-102, 2011-02. Faculty of Agriculture, Kyushu University

バージョン :

権利関係 : 


\title{
Basic Studies on Fracture Toughness of Sugi and Acoustic Emission
}

\section{Takeshi OHUCHI ${ }^{\text {** }}$, Andi HERMAWAN ${ }^{2}$ and Noboru FUJIMOTO ${ }^{2}$}

\author{
Laboratory of Wood Material Technology, Sustainable Bioresources Science, \\ Department of Agro-environmental Sciences, Faculty of Agriculture, \\ Kyushu University, Fukuoka 812-8581, Japanese \\ (Received October 29, 2010 and accepted November 8, 2010)
}

\begin{abstract}
The technique of such a fracture mechanics is hardly adopted in a wooden architectural field though a lot of large-scale wooden buildings are constructed. Therefore, the accumulation of basic data about these fracture toughness is necessary. Especially, the research on the fracture toughness of sugi (Cryptomeria japonica D. Don) expected as a material for the structure are hardly performed.

In this study, to obtain basic knowledge for the fracture toughness of sugi, compact tension (CT) specimens of six types (RL, TL, LT, RT, LR, and TR) with a different direction of the load and the crack progress in consideration of anisotropy were made from sugi. The fracture toughness tests with sugi CT specimen were conducted, and effects of the difference of both various CT specimens and load speed on the fracture toughness $\left(K_{I C}\right)$ were examined. In addition, acoustic emission (AE) generated during the test was measured, and the correspondence of the fracture toughness and $\mathrm{AE}$ was examined. The main results are summarized as follows: (1) for the sugi CT specimen in consideration of anisotropy, it was found that the specimen of two types of LR and LT was incompatible for the fracture toughness test in this study; (2) it was clear that the KIC of the sugi CT specimen shows constant values regardless of the load speed within the range of conditions in this test; (3) for the specimen of TR and RT that the crack progress direction was the vertical direction for the length direction, the $K_{I C}$ of TR was larger than that of RT; (4) the peaks in the AE average signal were admitted in the fracture process of the TR specimen and it corresponded to the position of the late wood part in progressing the crack. Therefore, AE technique is promising for the detection of the fracture process of the late wood part in the TR specimen.
\end{abstract}

\section{INTRODUCTION}

Recently, the fracture toughness which means resistance to the crack progress of the material with a crack is used as the base of the design stress to prevent the destruction of the general structure. The technique of such a fracture mechanics is hardly adopted in a wooden architectural field though a lot of large-scale wooden buildings are constructed. Therefore, the accumulation of basic data about these fracture toughness is necessary because wood and wood based-materials are used as the material for the structure with safety and high reliability more than before. However, there are few studies related to the fracture toughness of wood and wood based-materials. Especially, the research on the fracture toughness of sugi (Cryptomeria japonica D. Don) expected as a material for the structure are hardly performed.

In generally, the single edge notched (SEN) specimen or the compact tension (CT) specimen is used in the fracture toughness test. In a few previous studies on the fracture toughness of wood and wood based-materials (Sobue et al., 1985), the fracture toughness test used SEN specimen was conducted. However, it is difficult to make the SEN specimen for wood with anisotropy because the SEN specimen with large scale is needed a large log. On the other hand, the CT specimen can be

${ }^{1}$ Laboratory of Woodworking, Department of Technology, Fukuoka University of Education

${ }^{2}$ Laboratory of Wood Material Technology, Sustainable Bioresources Science, Department of Agro-environmental Sciences, Faculty of Agriculture, Kyushu University

* Corresponding author (E-mail: tohuchi@fukuoka-edu.ac.jp) adjusted to small shape and can be adjusted also to a small log. Therefore, the research on the fracture toughness is performed by using the CT specimen in the particleboard and MDF, and this is reported that the testing conditions influence the fracture toughness (Sato, 1988).

The objective of this study was to obtain basic knowledge for the fracture toughness of sugi. In this paper, sugi CT specimens of six types with a different direction of the load and the crack progress in consideration of anisotropy were prepared, and the fracture toughness tests were conducted based on American Society for Testing and Materials (ASTM) E 399-78. Effects of the difference of both various CT specimens and load speed on the fracture toughness were examined. In addition, acoustic emission (AE) generated during the test was measured, and the correspondence of the fracture toughness and $\mathrm{AE}$ was examined.

\section{MATERIALS AND METHODS}

Specimens in this study used sugi. The mean specific gravities and the mean moisture contents of specimens were 0.35 and $9.5 \%$, respectively. The CT specimen was made from sugi based on ASTM E 399-78. The shape of the CT specimen is shown in Fig. 1. First of all, after putting a notch of $28 \mathrm{~mm}$ in length with the bandsaw, the precrack of $2 \mathrm{~mm}$ is put in the bottom of the notch with the razor blade. Finally, the initial crack length was set to $20 \mathrm{~mm}$ as shown in Fig. 1. Moreover, the CT specimen of six types with the difference of both the load direction and the crack progress direction were prepared in consideration of anisotropy of sugi. That is, length (L), 


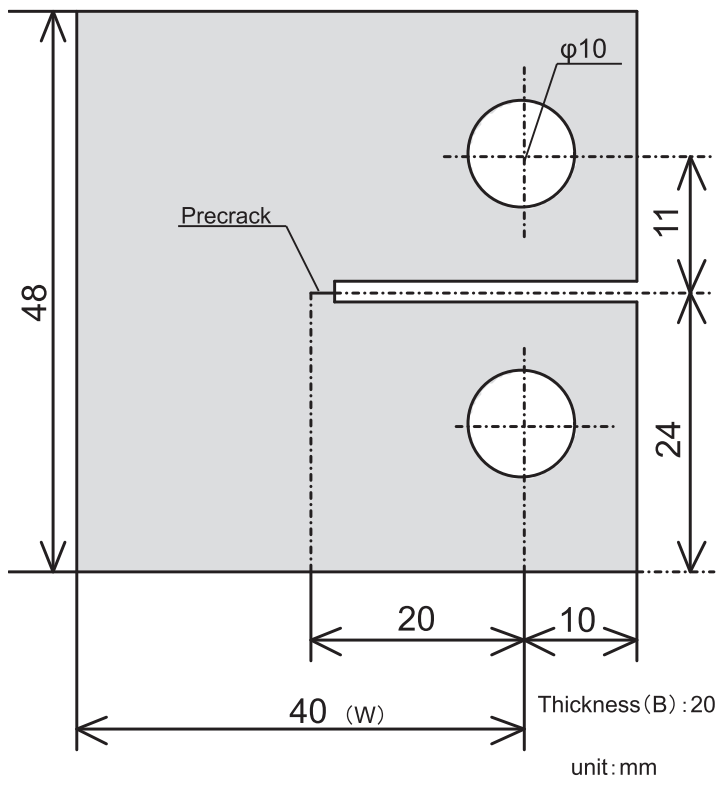

Fig. 1. Compact Tension (CT) specimen.

tangential $(\mathrm{T})$, and radial $(\mathrm{R})$ direction are combined, and the first character is defined as the load direction and the second character is defined as the crack progress direction. The CT specimen of six types was assumed to be RL, TL, LT, RT, LR, and TR.

Figure 2 shows a schematic diagram of the fracture toughness test with the CT specimen. The fracture toughness test for all CT specimens was conducted by using the Instron mode strength test machine. The load speed in tension was set in five steps of 0.5, 1.0, 2.0, 4.0, and $12.0 \mathrm{~mm} / \mathrm{min}$, respectively. In this test, the crack opening displacement was measured with the clip gauge at the same time in measuring the load with the load cell as shown in Fig. 2. In the measurement of AE, a AE sensor $(140 \mathrm{kHz}$ resonance frequency) is mounted on the middle point in a left corner of the CT specimen and the precrack point, and $\mathrm{AE}$ original signal generated during the test was amplified by $54 \mathrm{~dB}$ and then $100 \mathrm{kHz}$ highpass filtered with the $\mathrm{AE}$ tester, the $\mathrm{AE}$ average signal by half-wave rectification was measured.

The destruction toughness value $\left(K_{I C}\right)$ was mode I (Opening). Therefore, it calculated with the following equation.

$$
\begin{aligned}
K_{I C} & =\frac{P}{B W^{\frac{1}{2}}}\left[29.6\left(\frac{a}{W}\right)^{\frac{1}{2}}-185.5\left(\frac{a}{W}\right)^{\frac{3}{2}}\right. \\
& \left.+655.7\left(\frac{a}{W}\right)^{\frac{5}{2}}-1017\left(\frac{a}{W}\right)^{\frac{7}{2}}+638.9\left(\frac{a}{W}\right)^{\frac{9}{2}}\right]
\end{aligned}
$$

where $a$ is length from the center of the hole to the crack point $(\mathrm{mm}) ; B$ is thickness of specimen $(\mathrm{mm}) ; \mathrm{W}$ is width of specimen measured from the center of the hole, respectively $(\mathrm{mm})$. Moreover, the destruction point is considered to be a critical point, $P$ is assumed to be a maximum load value $(N)$.

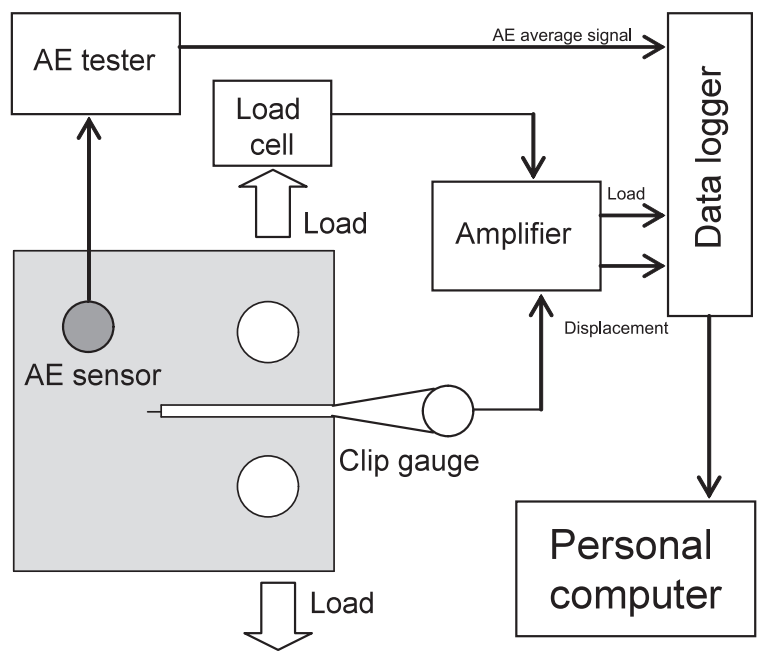

Fig. 2. Schematic diagram of fracture toughness test in this study.

\section{RESULTS AND DISCUSSION}

\section{Fracture form}

Figure 3 shows the fracture forms of various specimens after tests. Thus, it was able to be confirmed that the crack had progressed in the same direction as the precrack in the specimen of four types of RL, TL, TR, and $\mathrm{RT}$. On the other hand, in the specimen of two types of LR and RL, the crack caused along with the load had not progressed in the same direction as the precrack, and it had progressed in the length direction. Finally, the crack became a starting point, and the shear fracture was caused as shown in Fig. 3. From these results, we judged that the specimen of two types of LR and LT was incompatible for this test, and the fracture toughness in the specimen of four types of RL, TL, TR, and RT was targeted.

\section{Effect of load speed}

Figure 4 shows the typical relationships between $K_{I C}$ and load speed in the specimen of TL and RT. The $K_{I C}$ was almost unaffected by load speed and showed constant
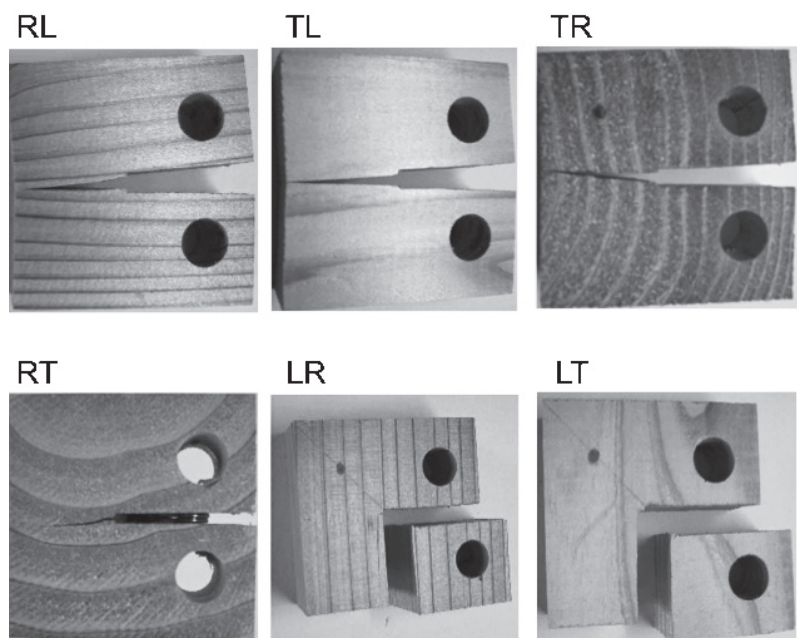

Fig. 3. Photograph of CT specimen after test. 


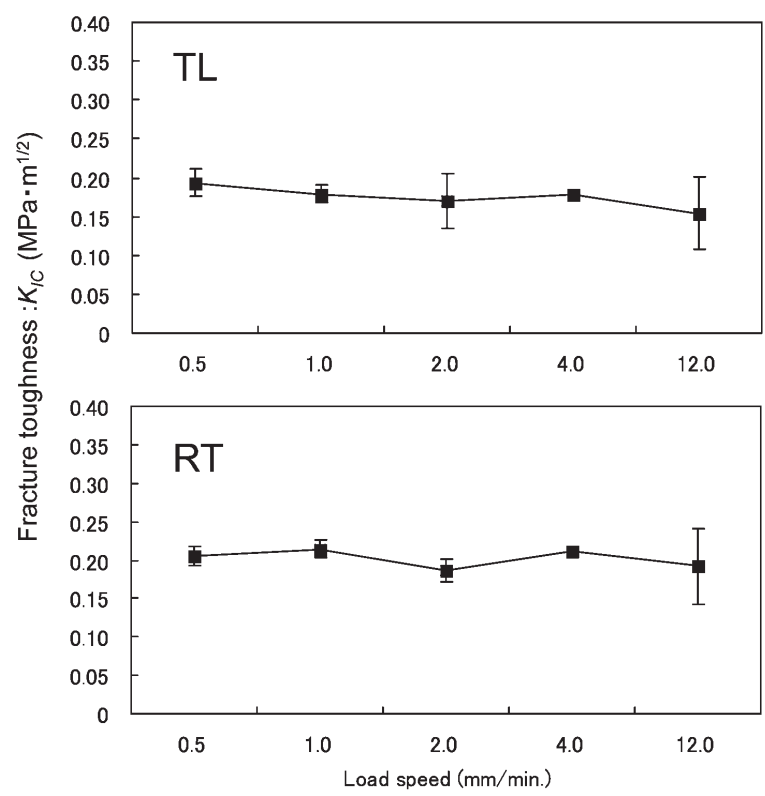

Fig. 4. Relationships between fracture toughness and load speed.

values. This tendency was similar under other specimens. From the result, it was clear that the $K_{I C}$ of the CT specimen shows constant values regardless of the load speed within the range of conditions in this test. Moreover, this result was corresponding to the report of Sato (1988).

\section{Fracture toughness in various CT specimen}

Figure 5 shows the typical relationships between $K_{I C}$ and various CT specimen in the load speed of $4 \mathrm{~mm} / \mathrm{min}$. In the specimen of RL and TL that the crack progress direction was the parallel direction for the length direction, the $K_{I C}$ of RL was larger than that of TL. It is considered that the tension of $\mathrm{R}$ direction in cross direction

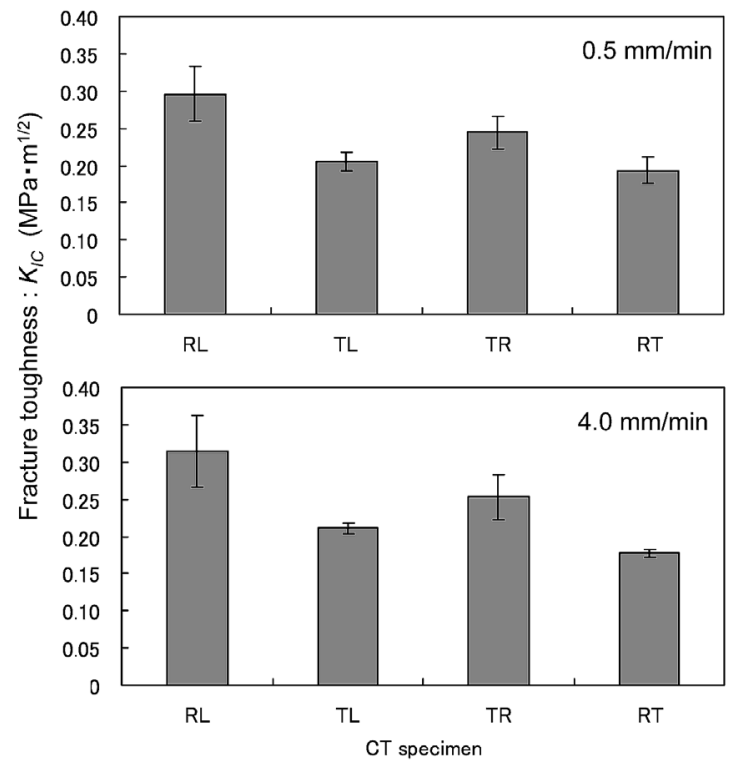

Fig. 5. Relationships between fracture toughness and CT specimen. is larger than that of $\mathrm{T}$ direction (Mokuzai Kogyo Hand Book, 2004). In the specimen of TR and RT that the crack progress direction was the vertical direction for the length direction, the $K_{I C}$ of TR was larger than that of RT. This is probably because the crack progress in the TR specimen crossed the annual ring and the fracture in the hard late wood was caused. On the other hand, the $K_{I C}$ of RT was small because all the crack progress in the RT specimen passed the soft early wood in the annual ring.

\section{AE average signal}

Figure 6 shows the typical relationships between load, $\mathrm{AE}$ average signal and opening displacement for TR- and RL specimen in the load speed of $1 \mathrm{~mm} / \mathrm{min}$, respectively. Two big peaks were admitted in the AE average signal in the fracture process of the TR specimen. These peaks corresponded to the position of the late wood part in progressing the crack. Therefore, the reason for these peaks is considered that $\mathrm{AE}$ was remarkably generated when the fracture in the late wood is caused. On the other hand, this tendency was not admitted in other specimen of three types of RL, TL, and RT. From these results, it was clear that $\mathrm{AE}$ technique is promising for the detection of the fracture process of the late wood part in the TR specimen.

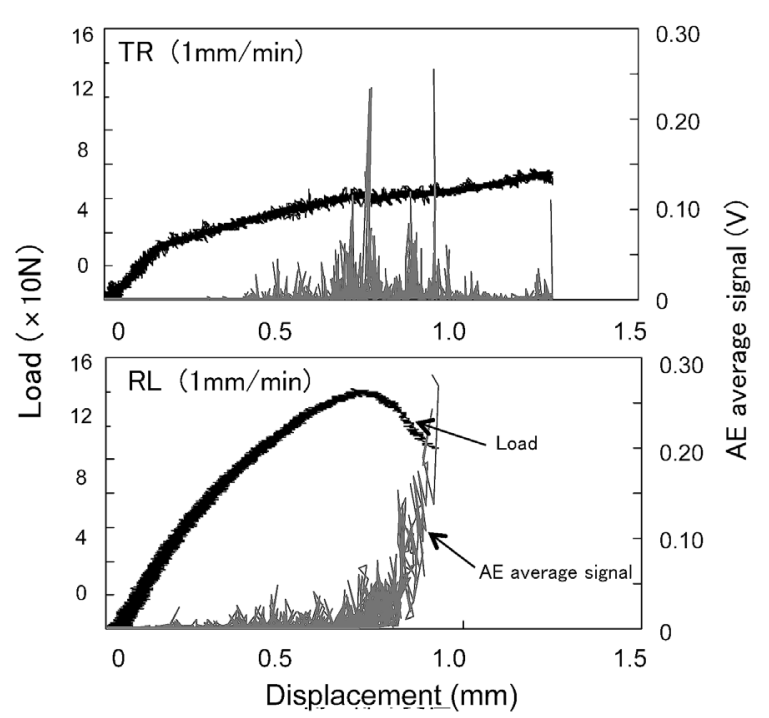

Fig. 6. Relationships between load, $\mathrm{AE}$ average signal and displacement.

\section{CONCLUSIONS}

In this study, the sugi compact tension (CT) specimen of six types with a different direction of the load and the crack progress in consideration of anisotropy were prepared, and the fracture toughness test was conducted based on ASTM E 399-78. Effects of the difference of both various CT specimens and the load speed on the fracture toughness $\left(K_{I C}\right)$ were examined. In addition, acoustic emission (AE) generated under the test was measured, and the correspondence of the fracture toughness and $\mathrm{AE}$ was examined. The main results are sum- 
marized as follows:

1) For the sugi CT specimen in consideration of anisotropy, it was found that the specimen of two types of LR and LT was incompatible for the fracture toughness test in this study.

2) It was clear that the $K_{I C}$ of the sugi CT specimen shows constant values regardless of the load speed within the range of conditions in this test.

3) For the specimen of $\mathrm{TR}$ and $\mathrm{RT}$ that the crack progress direction was the vertical direction for the length direction, the $K_{I C}$ of TR was larger than that of RT. This is probably because the crack progress in the TR specimen crossed the annual ring and the fracture in the hard late wood was caused. On the other hand, the $K_{I C}$ of RT was small as compared with that of TR because all the crack progress in the RT specimen passed the soft early wood in the annual ring.

4) The peaks in the $\mathrm{AE}$ average signal were admitted in the fracture process of the TR specimen and corresponded to the position of the late wood part in progressing the crack. On the other hand, this tendency was not admitted in other specimen of three types of RL, TL, and RT. From this result, it was clear that $\mathrm{AE}$ technique is promising for the detection of the fracture process of the late wood part in the TR specimen.

\section{REFERENCES}

Mokuzai Kogyo Hand Book (Fourth revision), 2004 Maruzen publishing, Tokyo, pp. 135-136

Sato K 1988 Influences of Specimen Size, Crack Length, Loading Rate, and Notch Acuity on Medium Density Fiberboard. Mokuzai Gakkaishi, 34(11): 955-958

Sobue N, Denis Bajolet, Guy Pluvinage 1985 Effect of Drying Stress on the Fracture Toughness of Wood (in English). Mokuzai Gakkaishi, 31(7): 528-531 